\title{
Administrative Policy for Stochastic Democracy
}

\author{
Peter J. Schubert, Ph.D., P.E. ${ }^{1}$ Senior Member AIAA, and Joe Sommer ${ }^{2}$ \\ ${ }^{1}$ IUPUI, Indianapolis, IN 46202, ${ }^{2}$ St. Charles North High School, St. Charles, IL 60175
}

\begin{abstract}
Prior studies of stochastic democracy have compared it to other forms of governance, demonstrated how to scale up or scale down as population changes, and developed an algorithm for start-up on Day 1. Left unanswered is the administrative policy for regulating the statutes developed by the legislative bodies. As the aim of stochastic democracy is design of a corruption-resistance form of managing human affairs the implementation of the activities of the government must also be robust against undue influence, bribery, and abuse of power. Decision-makers in a stochastic democracy by design cannot be "career" politicians, however, the bureaucrats of the government agencies or departments or ministries are advantageously retained across the changes in the legislative bodies. This quality invites corruption, the answer to which cannot be simply to apply oversight or policing. In this paper is developed an integrated structure which supplants the Byzantine-derived corporate-style hierarchy. Seven principles are applied to the bureaucracy and their integration and practice described herein as administrative policy, the principles being: transparency of regulatory process; not-less-than time limits; disclosure of change proposers; inclusion of economic externalities; open debate and notices of intent; chairmanship and participant selection; and periodic but stochastic changes in the number of agencies at each level of governance. This latter enforces either consolidation or expansion, within high and low limits, the reorganization of which will shuffle the reporting structure of the regulatory bureaucracy and disrupt entrenched habits and possible corrupting schemes. When complementing the legislative functions this work rounds-out the formation of a corruption-resistant, scalable form of truly representative governance for space habitats and societies of arbitrary size.
\end{abstract}

\section{Background}

$\mathrm{C}$ orruption is a widely despised but seemingly endemic feature of existing methods of human governance. Future space habitats which grow in population beyond the bounds of military command-and-control offer new possibilities to explore new methods of governance. Towards this end, Stochasticism, also known as Stochastic Democracy, was introduced and compared to other forms of governance such as Communism (pure), Capitalism (selfinterest), and Elitism (priviledged). Agent-based simulations used with diverse, isolated populations interacting daily with their government within a sealed habitat for 10 years demonstrated Stochasticism to achieve the fewest deaths, greatest productivity, and a more balanced distribution of income than either Capitalism or Elitism ${ }^{1}$. Space habitats may change rapidly, possibly drastically, whether an increase from the arrival of a generation ship or exodus, or a decrease from a decimation by disease or meteorite impact. A second study explored the ability of multi-level Stochastic Democracy government districting to scale up or down by factors of 10 or more using the k-means function, finding this to be sufficient ${ }^{2}$. A third study investigated the start-up of a Stochastic Democracy government system within a single day (Day 1), such as may be required upon a sudden change in circumstance like a collapse of a prior government. In addition to populating the entire hierarchy of decision-makers for a 4 level government representing a population of 3,500,000, the start-up algorithm also facilitated a smooth transition to a perpetuating sequence of balanced and overlapping service terms by Year $4^{3}$. These three studies complete the formulation of the legislative body, but beg the question of the agencies, departments, or ministries needed to enact, regulate, and implement such decisions and laws as are developed by legislators at each level of the government. Thus the current work provides necessary and complementary guidance on the full development of a corruption-resistant government according to the principles of Stochastic Democracy, these being to introduce randomness within constraints so as to thwart undue influence, bribery, and abuse of power.

\section{Introduction}

Seven aspects of regulatory agencies are outlined which, working in concert and integrated with the legislative body, extend the principles of Stochastic Democracy to rule-making, rule changes, and the process by which these are derived. One might argue that corruption of the bureacracy is less of a concern than the law-making body, and while 
this may be true there can exist considerable motivation for exerting influence by those who would be affected by regulations. Of course, the regulators must work within the strictures of the laws and statutes of the legislative body, however a desireable quality of a law is that it spells out the goals, objectives, or limits without defining precisely how these are accomplished. Thus, steps to reduce undue influence, bribery, and abuse of power in the regulatory agencies is a worthy endeavor. Furthermore, while bureacratic agencies benefit from the experience and tribal member of longserving public employees these same valued individuals and their culture can become stagnant, hide-bound, lugubrious, and non-responsive. Therefore means to keep this work "fresh" will be introduced using stochastic principles.

Principles of administration in a stochastic democracy apply to regulatory activities in the implementation of statutes developed by the legislative body described in earlier studies of this novel form of governance. In each case the application of principles of stochastic, or structured randomness, introduce a means by which to preclude the ability to determine outcomes and thus frustrate the efforts of certain actors to unduly influence the rule-making and enforcement of the government. The principle of stochasticism aims to provide, over time, the will of the citizens to be properly represented in their system of government.

\section{Methods}

Numerical parameters described herein are designed to be general guidelines and algorithms explained are intended to provide principles of operation however the future development of technology, human life, and the structure of civilization writ large may change and adapt over time so there should be provisions by which slow and gradual adjustements of these parameters and algorithms can be brought into play. Finally, there must be a threshold at which rules and regulations give back over to legislation such that there is balance between the political principles and legal framework of the laws and the practical implementation of the means by which they are put into action. Subsections below outline each of the seven key principles of administration of Stochastic Democracy in light of these considerations.

\section{III.1. Transparency of regulatory process}

Transparency is an obvious quality desired for rule-making. This must include, both during the rule-making process and preserved in the rule itself for consideration of future changes the reasons and motivations for the rule, the research conducted in developing it, considerations for possible future situations which may impact the rule, and disclosure of the parties involved and the sources of funds used by the parties in the development of the rule. Explicitly the following should be considered as fields to be completed in documentation of the rulemaking process:
Reasons
Rationales
Considerations
Balances
Compromises
Conditions
Tradeoffs
Assumptions
Opposing Viewpoints

Documentation must be provided for each step or compilation in the process, namely: Announcement; Materials; Proceedings/Minutes; Judgement; Decisions; Rules/Regulations; Penalties; Prosecution (intermediate steps).

There exist legitimate reasons to limit transparency, including: respect for individual privacy; considerations of national security; and non-disclosure of proprietary information of material value to a business or corporation. In every case the rulemaking committee must set a time limit beyond which redacted or secreted information may be revealed. Furthermore there should be a due process of discovery by which interested parties may petition for the restricted information to be disclosed so as to provide for special cases too specific or peculiar to anticipate in advance. Secret, restricted, confidential, proprietary, or redacted information should be considered a perishable commodity such that the more time which has passed the lower the threshold for release.

\section{III.2. Not-less-than time limits}

Being transparent in operations must include advance notice. Only with sufficient time can those who would be subject to, or stakeholders in, a rule or regulation conduct their own evaluation and prepare their own inputs to the process. How much time is a matter of the speed of communication which may, in the case of widely distributed realms in space, experience significant delays simply due to the finite speed of electromagnetic waves. It must also be considered that not every citizen will desire to be involved in every matter under consideration, therefore there must not be placed upon each person an undue amount of information to be processed. Considering that a government is only suitable when there is interaction among citizens and a sufficient density of them that most will have discourse with their fellows, a probabilistic means may be used to guide the degree to which efforts must be undertaken to 
communicate a change in rules or regulations. Taking into account both dissemination and advance notice the following two principles are proposed to guide the transparency process:

(1) At leat 10 percent of the population has a 90 percent change to know of the proposed rulemaking in sufficient time that their earliest possible response is no less than 2 weeks in advance of the hearing of the arguments, and;

(2) At least 67 percent of the population can learn or access the information with no more than 20 minutes of effort such that their earliest possible reaction thereto is no less than 2 weeks in advance of the hearing.

\section{III.3. Disclosure of change proposers}

Changes are generally proposed by those stakeholders who either seek benefit or to avoid detriment by said change. It is to be expected that certain such stakeholders may not wish their intentions or motivations to be known, such as for example, if they might expect an unfair and significant reward from the change. There should be no impediment to stakeholders receiving benefits or avoiding detriments but their motivations should be laid bare to the greatest extent possible so that the matter can be decided with the greatest amount of information. A quote from the financier J.P. Morgan is apt here: "A man generally has two reasons for doing a thing. One that sounds good, and a real one. For the administration of proposed rulemaking in a stochastic democracy a reasonable requirement is to ask for three reasons, each being non-trivial, with the aim that the primary motivation be made manifest. Another method used by change proposers to mask their motives is to employ a front, either person or organization, and providing that entity with some motivation so that said entity may list motivations which appear prima facie to be whole. To completely preclude graft in such disclosure may always be unattainable as many humans are experts at dissembling, telling partial truths, and masking true motivations. It must therefore be recognized that, in the absence of perfection, a public record of disclosure be kept so that over time the population may become aware of those entities which fail to fully and properly disclose their motivations and reasons. Therefore each stakeholder proposing a change must swear and sign an affidavit containing the information outlined below. To swear here means to give one's word of honor, or to stake one's reputation, or to beg to be trusted. The guiding principle being the aphorism from Randall Terry: "Fool me once, shame on you. Fool me twice, shame on me". The affidavit of each change proposer must disclose non-trivial responses to the following:

(1) Personal/Individual

a. Income received

b. Non-cash acquisitions received

c. Services render or entertainment provided

d. Promises or assurances of the above

(2) Immediate Family/Guardian Members

a. Income received

b. Non-cash acquisitions received

c. Services render or entertainment provided

d. Promises or assurances of the above

(3) Corporations or Trusts in which the proposer is a party
a. Income received
b. Non-cash acquisitions received
c. Services render or entertainment provided
d. Promises or assurances of the above

\section{III.4. Inclusion of economic externalities}

An economic externality is a non-costed boon or harm incurred either by the parties directly involved or by third parties indirectly affected. Externalities may be known by those affected, or they may be unknown. Thus, by nature it is difficult nigh unto impossible to identify all economic externalities. Nor is it efficient to put a cost onto every conceivable impact of a decision, action, or rule, as such may be continued ad infinitum and thus ad absurdum. The goal of including such externalities in consideration is to inform the citizens, making them aware of the possibilities. It is well known that the principles of some economic theories suggest that an informed marketplace is efficient and therefore brings a general benefit to all. While perfect information is considered ideal but generally unattainable, the information provided to citizens according to the principles of transparency described above should include both the positive and negative non-costed externalities for the following categories:

(A) Medical or health impacts

(B) Environment and climate impacts

(C) Effects on access and opportunity

American Institute of Aeronautics and Astronautics 
(D) Nuisances of sound and sight

(E) Nuisances of time or the burden of effort

(F) Aesthetic consideration and the impact on appreciation of culture or nature

In studies of economic externalities the impact on the public can be modified by a so-called Pigouvian tax which shifts the price/quantity curve for a given product or service. The aim herein is not to impose more complex taxes, however, during the course of debate and discourse in rulemaking it may become evident that new legislation is required. Should the proceedings become overly lengthy by the involvement of more than one interest (to preclude stonewalling or filibustering) the administrative body may recommend to the legislative body to take the matter under advisement.

\section{III.5. Open debate and notices of intent}

Summarizing and completing the analysis of the prior 4 principles the specific nature of the notice of intent can be stated. This must disclose to all parties the benefits expected or the detriments to be avoided for each stakeholder interested to participate. The process is started by the proposer, who follows the format listed below, and then is continued by each stakeholder contributing their own "plusses and minuses" analysis using the same template or format. Entries should be made as simple as possible and no simpler (to paraphrase A. Einstein) using common language such that those analyzing and summarizing the responses may aggregate them to such a degree that the information provided to the administrative body is neither too trivial nor too voluminous. Guidance on this balance may change depending on the nature of the issue at hand, but also must balance practical issues of timing as will be described in the next principle whereby nearly all issues should be resolved within a reasonable time frame aligned with the chairmanship of the rulemaking committee. If this timing is not met the administrative body may recommend to the legislative body that the matter be taken under advisement. Each stakeholder should provide cogent, brief, and succint responses in the following format:

\begin{tabular}{|l|c|c|}
\hline ENTITY IMPACTED & BENEFITS & DETRIMENTS \\
\hline You alone & non-trivial response & $"$ \\
\hline Your family or protectorates & $"$ & $"$ \\
\hline Your corporation or trust & $"$ & $"$ \\
\hline Your locality, region, or nation & $"$ & $"$ \\
\hline
\end{tabular}

\section{III.6 Chairmanship and participant selection}

Chairman and any other gender-specific term in this work is taken as a linguistic simplification of chairwoman, chairperson, or chairman and in no way implies bias of gender or otherwise. There may conceivable develop conditions whereby non-biological entities are considered for positions of responsibility in a stochastic democracy and the terminology herein should not be taken to preclude such. Durations are based on an earth year in 2018 with the understanding this is not a constant, and furthermore that the pace of human and intellectual development may accelerate or may slow in the future, thus the parameters selected here are intended as guidelines which may be modified gradually and incrementally by action of the legislative body of a stochastic democracy.

The administration of a stochastic government is divided into ministries, and sub-divided into departments as explained in the next section. Each department head is responsible to maintain a workforce sufficient to conduct the activities allocated by the Minister. The Minister is selected by the legislative body on the basis of merit and is reinstated or replaced on a yearly basis. Whereupon the ministry is charged with creating or modifying a rule or regulation the Minister designates a lead department and the department head forms a rulemaking committee.

The rulemaking committee composition must include members of the general public who have contributed a benefits and detriments response per section III.5 above. As part of the submission process said members may indicate if they are willing to serve on a committee, or they may opt out. The department head is to select an initial committee membership consisting of members of his staff with appropriate expertise. The initial committee shall follow an algorithm by which to identify willing members of the general public having contributed a benefits and detriments response which represents in a nearly optimal manner the clusters of such responses from the public. The size of the rulemaking committee shall be set by the Minister when informing the department of the proposed rulemaking and may range from 5 to 40 members depending on the complexity of the issue. The Minister should provide a succint justification of the selection of size which becomes part of the public record. Whenever possible, the Minister should recommend and encourage a former legislator to participate as a committee member. The fraction of the rulemaking committee comprised of staff members of the department plus former legislators should be slightly less than half. Votes on the elements of a rule or regulation must prevail by a two-thirds majority of the committee members. 
Dissenting members must record their objections and recommendations as part of the documenting containing the final rule.

Each rulemaking committee shall have a chairman and a vice-chairman, also a secretary and vice-secretary, the latter two of which are responsible for capturing a record of the proceedings, ensuring the completeness and security of the documents included, considered, and submitted, and the publication of the document containing the final rule, subject to approval by the chair, the department head, and the Minister. The chairman shall be determined by random lot from the committee with equal probability applying to each member. The vice-chairman is selected by random lot of the remaining committee with equal probability exclusive of the chairman. The chairman may quit at any time, and if the chairman quits, or becomes incapable of executing his duties, then a new chairman AND a new vice-chairman are selected in the same way. This provision discourages bad actors from malicious acts towards the chairman in hopes that the vice-chairman might advance.

Figure 1 shows the duration of the charimanship as a probability distribution function with a peak value at 1.33 years decreasing monotonically to zero at 0.67 years and 2.0 years such that the area under the curve is unity. At the conclusion of the duration of chairmanship a stochastic selection is made to either (a) retain the chairman, or (b) replace the chairman by advancing the vice-chairman, using the probability weighting shown in the right side of Fig. 1. Upon the advancement of the vice-chairman to chairman, another vice-chairman is selected by random lot exclusive of the now-chairman, but inclusive of the prior chairman.

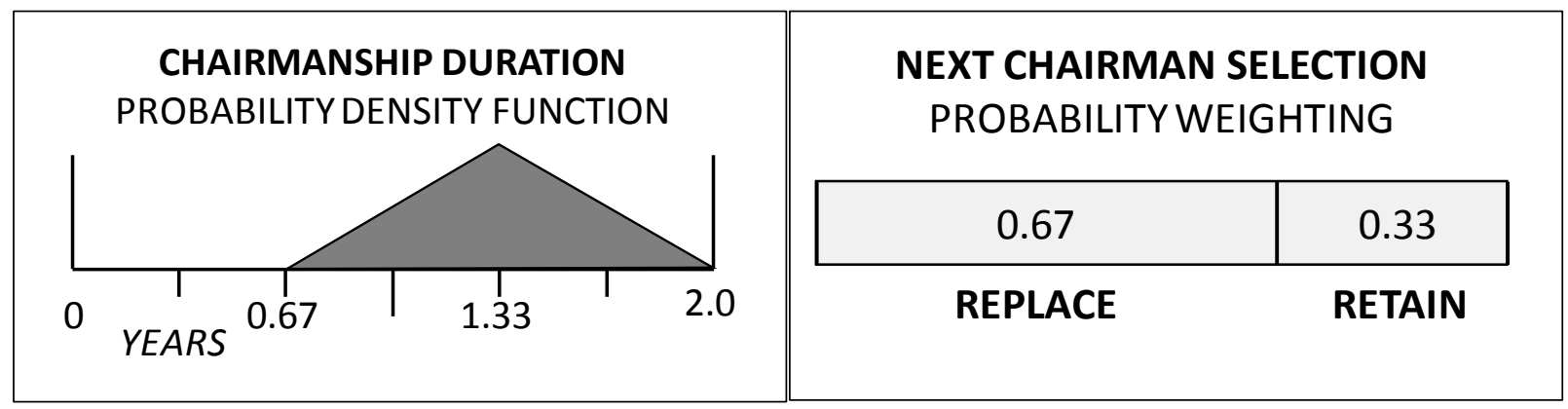

FIGURE 1. Probability functions for chairmanship duration and selection of the next chairman. Mean chairmanship duration is 1.33 years with a 1/3 likelihood of a second term (and 1/9 for a third term, etc.).

The expected duration for chairmanship is calculated from the expression below, and in the limit approaches 2 years.

$$
D=\sum_{i=0}^{\infty}\left(\frac{1}{3}\right)^{i} 1.33 \overline{3}
$$

\section{III.7. Periodic but stochastic changes in the number of agencies at each level of governance}

Finally, a key part of a stochastic form of governance is introduced by changing the number of agencies at a given level of government. Too few agencies consolidate too much control and create too much bureacracy, while too many generates inefficiencies and over-specialization through which some issues may pass without finding a proper home. Shaking up the number of agencies between limits of too few and too many is to happen at an aperiodic rate determined by a random variable. While such re-organizations will introduce a certain amount of waste and delay to process, it also prevents stagnation, endemic entrenched thinking, excess concretization of positions, and increases the potential for innovation.

$$
C(\boldsymbol{n}, \boldsymbol{r})=\frac{\boldsymbol{n} !}{(\boldsymbol{r} !(\boldsymbol{n}-\boldsymbol{r}) !)}
$$

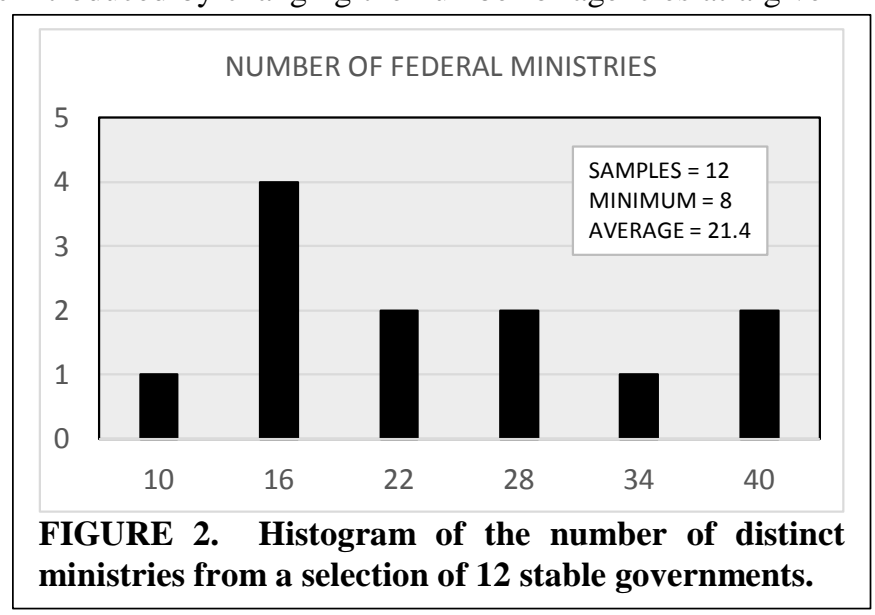




\begin{tabular}{|r|l|l|l|}
\hline MINISTRY & Department & Department & Department \\
\hline 1 & Business & Economy & Jobs \\
\hline 2 & Energy & Power & Distribution \\
\hline 3 & Diplomacy & Policy & Aid \\
\hline 4 & War & Security & Defense \\
\hline 5 & Justice/Law & Equity & Dispute Resolution \\
\hline 6 & Agriculture & Water/Land/Air Resources & Food \\
\hline 7 & Enviro./Ecology & Basic Science & Engineering Research \\
\hline 8 & Education/Arts & Youth \& Family & Homes \\
\hline 9 & Aviation/Space & Transportation & Infrastructure \\
\hline 10 & Communications & Media & Advertising \\
\hline 11 & Medicine & Health & Quality of Life \\
\hline 12 & Treasury/Taxes & Finance & Banking/Currency \\
\hline
\end{tabular}

FIGURE 3. Initial point for 12 ministries each with 3 departments.

\section{Results}

We obtained graphical and numeric results by conducting research into the organization of a corruption-resistant government based upon the compatibility of stochastically assigned departments, that could be used in future colonies in space. The methodology utilized involved creating a computer program to organize and evaluate the compatibility of the departments being compared. We then created and conducted a survey to obtain the opinion of the public on the level of compatibility of the stochastically assigned departments. The survey results were used to create the Department Compatibility Matrix (Figure 4), which is then used in the computer program to create potential pairings for a corruption resistant stochastic government. We also created a program that ensures that every department has a pair and every department is used.

Initially, we created a Department Compatibility Matrix using the 36 departments from Figure 3. The 36x36 matrix has a rating of compatibility for every combination of departments. Then we created a computer program (using MATLAB) that stochastically paired two departments together. In order for the program to function, we manually input one row from the Department Compatibility Matrix and then the code displays two numbers that correspond to 2 departments in the matrix. This method was used to build the survey questions. The program would ultimately rely on the ratings (the level of compatibility) from the Department Compatibility Matrix to shuffle the regulatory bureaucracy and reorganize departments at a given level of government (Figure 4).

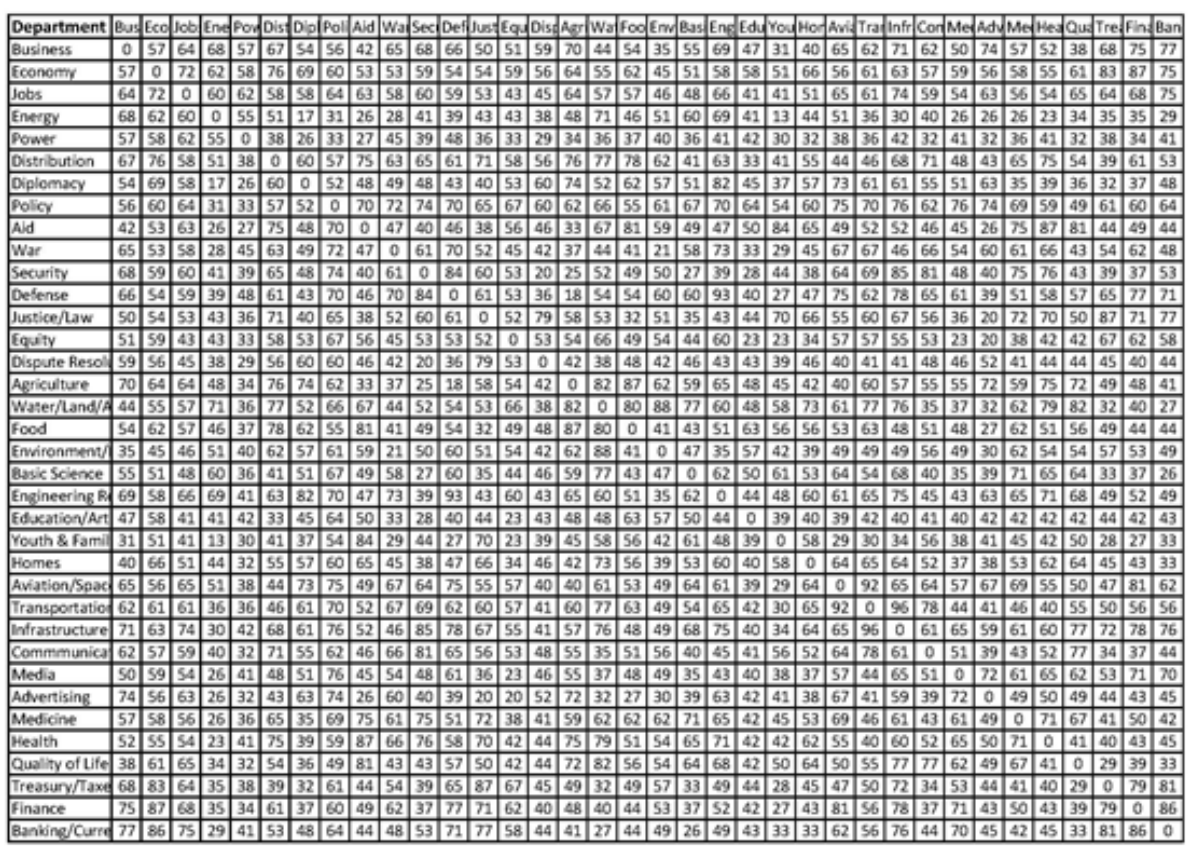

FIGURE 4. Department Compatibility Matrix, from survey (symmetric).

American Institute of Aeronautics and Astronautics 
In order to get the ratings for the Department Compatibility Matrix we created 18 different surveys containing 35 questions each; these 18 different surveys accounted for every possible combination within the Department Compatibility Matrix. Each question in the survey was a slight variation of the template, "On a scale of 1-100, how compatible are the (DEPARTMENT 1) and (DEPARTMENT 2) departments in government?” We broadcast to approximately 300 people through social media and direct email to gain assistance in distributing the survey and obtaining survey responses. The large number of people reached included those with a social media following and those with a connection to the research field, for example government, science, and technology. The average response across all compatibility ratings was 53 with a standard deviation of 15, with the range extending from 13 (Energy v. Youth\&Family) to 96 (Transportation v. Infrastructure). Figure 5 shows a histogram of the result from 67 returned survey responses, a sufficient number that each of the 36x36 combinations was evaluated no fewer than three times.

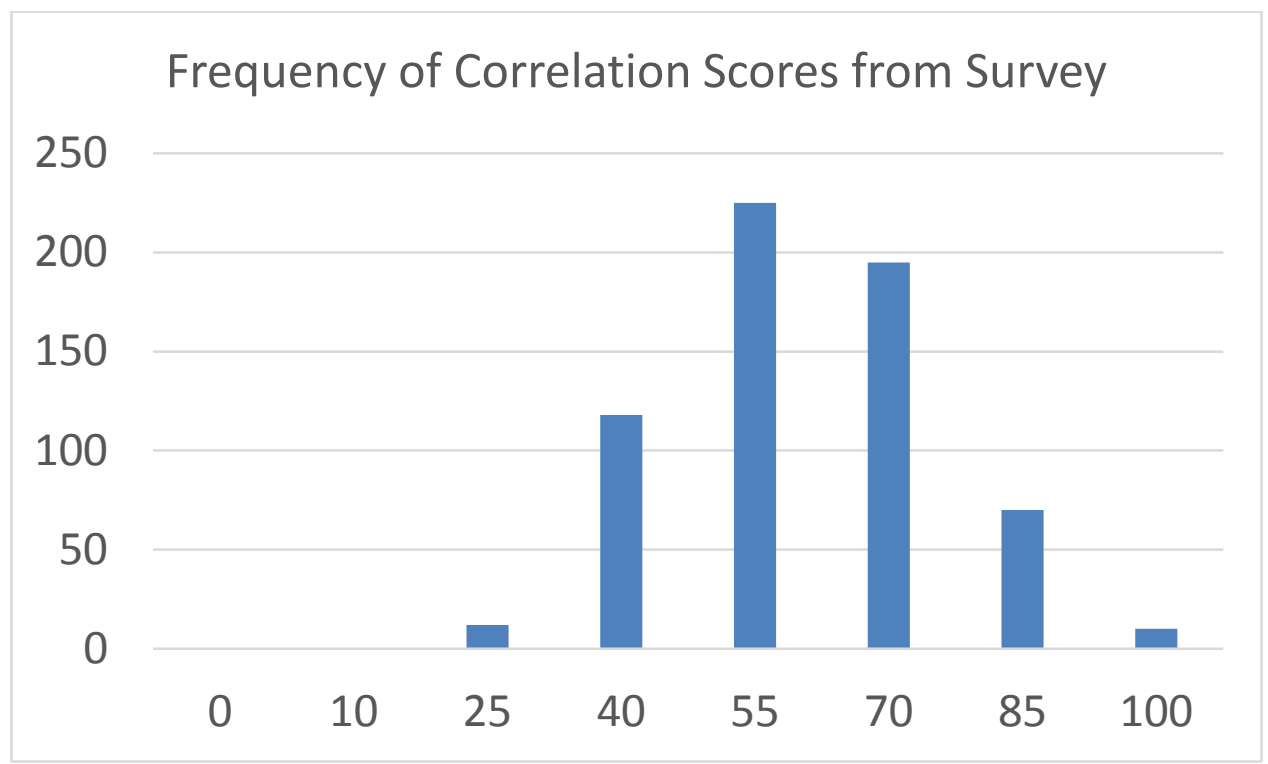

FIGURE 5. Survey results for correlations between all departments $(\mathrm{N}=67)$.

Finally, the results from each survey question are averaged to form the corresponding rating in the Department Compatibility Matrix. These ratings are then used within the computer program to stochastically pair the 36 departments. A potential organization of departments based on the current Department Compatibility Matrix is depicted in Figure 6. The software code and the survey were designed to ensure that all governmental departments were used and that each had a pair. Based on the stochastically generated pairings from the results we obtained, it is unlikely that one could have predicted the combinations, and therefore this strategy for organizing government is corruption-resistant.

\section{Discussion \& Recommendations}

Employee management within an agency should avoid conflict with the regulated industry, and should minimize opportunities for influence by industry through bribery, coercion, or threats. Private operation or control of the bureacracy is to be avoided so as to preclude the profit motive influencing rule-making and regulation. Permanent employees must have the highest degree of indepedence applied to the hiring process and retainment process. Promotion within the organization is primarily via advancement of permanent employees, with there being a reasonable amount of cross-agency staff movement to bring in fresh ideas and methods of management. Pursuit of advanced degrees, paid by the agency, is to be encouraged for higher level staff members. Contract employee ranks may swell or dwindle based on the quantity of work. Contract employees are generally at the lowest level of the bureacracy, they may have conflicts, but will have minimal influence on their superiors and the overall function of the organization. Contracts of finite duration, with provisions for changeover of staff, with a detailed review for conflicts for renewal. Promotion within the organization is primarily via advancement of permanent employees, with there being a reasonable amount of cross-agency staff movement to bring in fresh ideas and methods of management. 
Pursuit of advanced degrees, paid by the agency, is to be encouraged for higher level staff members. Contracts of three years, with a detailed review for conflicts for renewal. Promotion for longevity of service should be positive, but modest. Pay schedule should be common across agencies and decided upon by the legislative body. Survey results indicate the plausibility of using public opinion as a guide in organizing this new corruption-resistant government.

\begin{tabular}{|c|}
\hline Stochastically Generated Pairs \\
\hline Business - Treasury/Taxes \\
\hline Economy - Distribution \\
\hline Jobs - Quality of Life \\
\hline Energy - Education/Arts \\
\hline Power - War \\
\hline Diplomacy - Agriculture \\
\hline Policy - Homes \\
\hline Aid - Finance \\
\hline Security - Banking/Currency \\
\hline Defense - Water/Land/Air Resources \\
\hline Justice/Law - Health \\
\hline Equity - Medicine \\
\hline Dispute Resolution - Aviation/Space \\
\hline Food - Communication \\
\hline Environment/Ecology - Basic Science \\
\hline Engineering Research - Infrastructure \\
\hline Youth \& Family - Advertising \\
\hline Transportation - Media \\
\hline
\end{tabular}

Figure 6. One arrangement of Departmental pairings based on public survey results.

\section{References}

${ }^{1}$ Schubert, P., “A Novel System of Governance for Remote Communities,” AIAA SPACE 2010, Anaheim, CA30 Aug-2 Sept 2010.

${ }^{2}$ Schubert, P., "Start-up and Scale-up of a Novel Form of Colony Governance,” AIAA Space 2013, San Diego, 9-11 Sept 2013.

${ }^{3}$ Schubert, P., "Selection and Re-Selection in Stochastic Democracy," Proceedings AIAA SPACE 2015, Pasadena, CA, 31 Aug. - 2 Sept. 2015. 